\title{
Immunology of Endometriosis; a Systematic Review
}

\section{ART ICLE INF O}

\section{Article Type}

Systematic Review

\section{Authors}

Roumandeh N. ${ }^{1} M s c$

Saremi A. ${ }^{1} M D$

Zare A.* PhD

\section{How to cite this article}

Roumandeh N, Saremi A, Zare A.

Immunology of Endometriosis; a Systematic Review. Sarem Journal of Reproductive Medicine. 2019 ;3(1):25-31.
*"Sarem Fertility \& Infertility Research Center (SAFIR)" and "Sarem Cell Research Center (SCRC)", Sarem Women Hospital, Tehran, Iran ${ }^{1 " S a r e m ~ F e r t i l i t y ~ \& ~ I n f e r t i l i t y ~ R e-~}$ search Center (SAFIR)" and "Sarem Cell Research Center (SCRC)", Sarem Women Hospital, Tehran, Iran

\section{Correspondence}

Address: Sarem Women Hospital, Basij Square, Phase 3, Ekbatan Town, Tehran, Iran. Postal Code: 1396956111

Phone: +98 (21) 44670888

Fax: $+98(21) 44670432$

zare-a@alumnus.tums.ac.ir

\section{Article History}

Received: July 12, 2017

Accepted:September28,2017

ePublished: January 4, 2019

\section{A B S T R A C T}

Background Endometriosis is a common and gynecologic illness affecting women in reproductive age and characterized by the growth of endometrial-like tissue and stroma outside the uterine cavity. It is also a significant cause of infertility. The cause of endometeriosis is still unclear but an increasing number of studies have been investigated the role of immune system in its etiology and pathogenesis. So, it is well known that endometriosis is an inflammatory disease and has dysfunction in patient's immune response. The development of endometriosis may be influenced by immune factors including formation of autoantibodies, impaired immune recognition and clearance of ectopic endometrial cells. In this review, we will summarize the current knowledge about immunological factors in women with endometriosis that provide the basis for developing new approaches to patient management.

In this review, the basic contents were obtained from textbooks and new surveies were searched from pubmed, science direct and google scholar in the period of 1980-2015.

Conclusion Immunological factors have been considered as important factors in the prevention and treatment of endometriosis. In addition, clinical studies are recommended to understanding the mechanism and the role of immunological factors in the prevention and treatment of endometriosis.

Keywords Endometriosis; Immunology

\section{CIT A T I O N L INKS}

[1] Immunology of endometriosis [2] Natural killer cells: Key players in endometriosis [3] Enhancement of human monocyte and peritoneal macrophage chemiluminescence activities in women with endometriosis [4] Spontaneous and induced synthesis of cytokines by peripheral blood monocytes in patients with endometriosis [5] Peritoneal fluid-mediated enhancement of eutopic and ectopic endometrial cell proliferation is dependenton tumor necrosis factor-alphain women with endometriosis [6] Immunological aspects of endometriosis [7] Atherosclerosis, oxidation and endometriosis [8] The development of cytotoxicity in peritoneal macrophages from women with endometriosis [9] Modulation of neutrophil apoptosis by plasma and peritoneal fluid from patients with advanced endometriosis [10] Dendritic cell populations in the eutopic and ectopic endometrium of women with endometriosis [11] Immunobiology of endometriosis [12] Targeting mast cells in endometriosis with janus kinase 3 inhibitor, JANEX-1 [13] Clinical immunological aspects of genital endometriosis [14] The effect of estradiol on the production and secretion of complement component 3 by the rat uterus and surgically induced endometriotic tissue [15] Is endometriosis an autoimmune disease? [16] Autoimmunity in infertile patients with endometriosis [17] Endometriosis: can it produce an autoimmune response resulting in infertility? [18] Autoimmunity to endometrium and ovary in endometriosis [19] Autoimmunity in endometriosis: Relevance to infertility [20] Is adenomyosis an immune disease? [21] The effect of endometriosis, its stage and activity, and of autoantibodies on in vitro fertilization and embryo transfer success rates [22] Treating endometriosis as an autoimmune disease [23] Deficient cellular immunity in endometriosis [24] Immunological aspects of endometriosis: A review [25] T regulatory lymphocytes in patients with endometriosis [26] Interleukin-17 and type 17 helper T cells [27] Th17 cells in human disease [28] Recruitment of CCR6-expressing Th17 cells by CCL 20 secreted from IL-1 beta-, TNF-alpha-, and IL-17A-stimulated endometriotic stromal cells [29] Immunological aspects of endometriosis : an update 
بيمارى نقش بالقوه اجزاى ايمونولوزيك را شرح دادهايم. هدف از

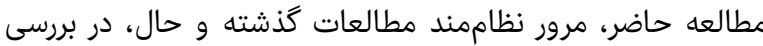
اهميت سيستم ايمنى در پِاتوثنز آندومتريوز بود.

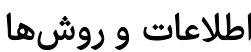

مطالب يايه و مفاهيم اصلى و اساسى از كتابهاى مرجع استئ استخراج

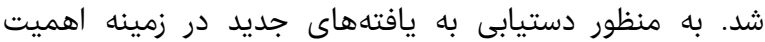

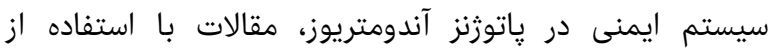

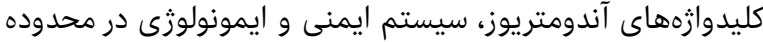

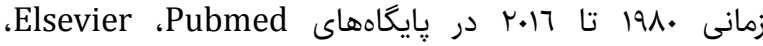
Google Scholar و Science Direct ،Springer جستوجو قرار كرفتند. از اين ميان مقالات يزوهششى اصيل و

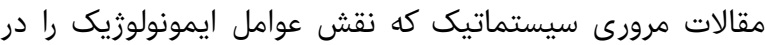

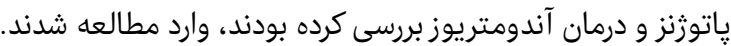

\section{يافتهها \\ ايمنى ذاتى إيتها}

سلولهاى ايمنى و محصولات آنها كليد شناسايى و پپاكسازى مخى

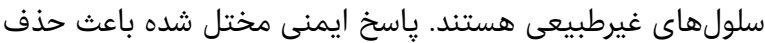

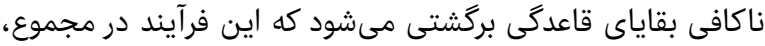

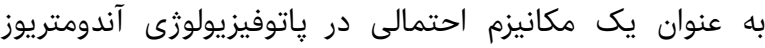

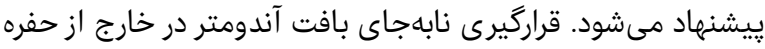

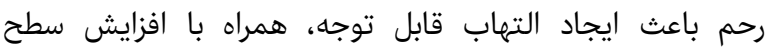

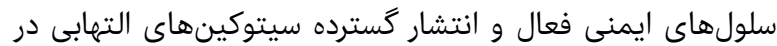

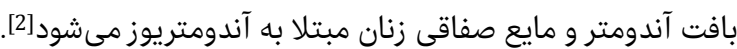

ماكروفازٔها

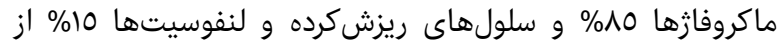

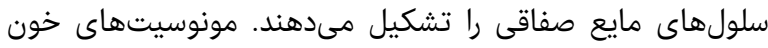

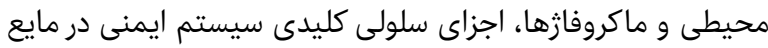

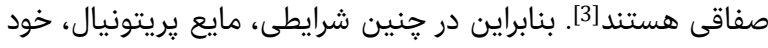

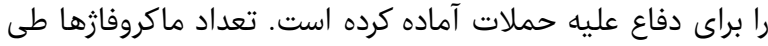

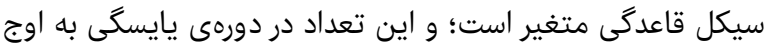

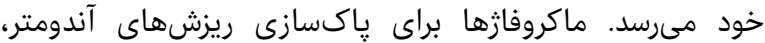

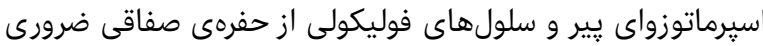

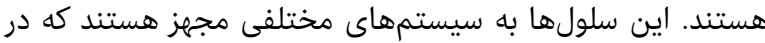

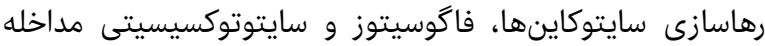

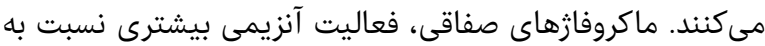

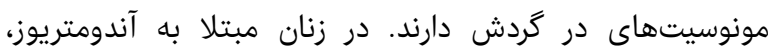

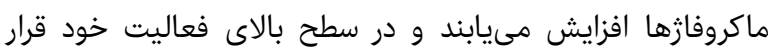

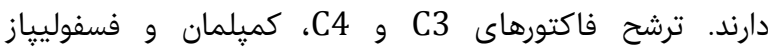

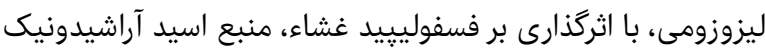

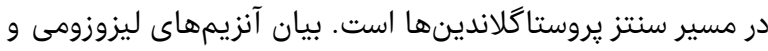

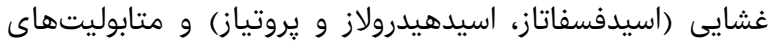

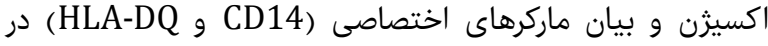

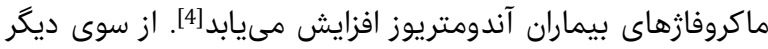

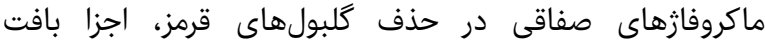

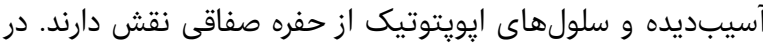

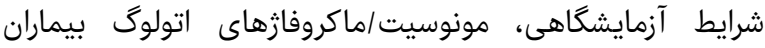

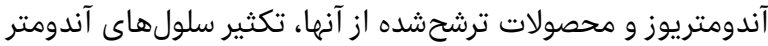

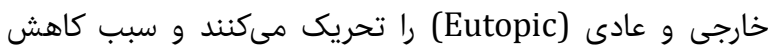

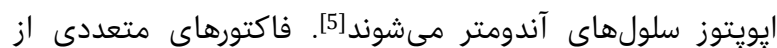

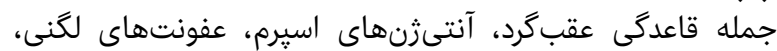

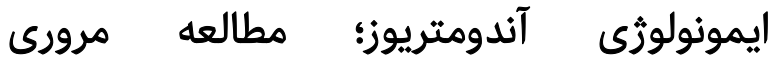

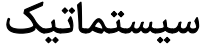

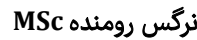

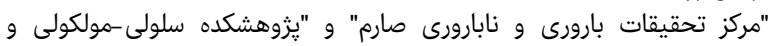
سلولهاى بنيادى صارم"، بيمارستان فوق تخصصى صارئ صارم، تهران، ايران

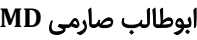

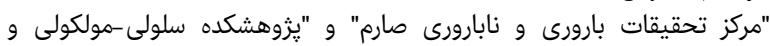
سلولهاى بنيادى صارم"، بيمارستان فوق تخصصى صارم، تهارئ تهران، ايران

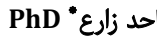

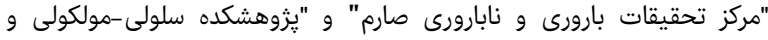

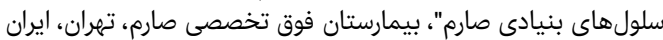

קكيده

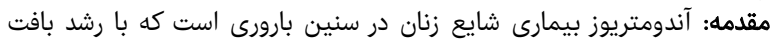

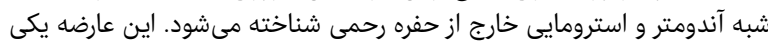

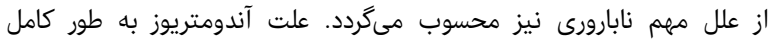

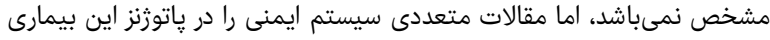

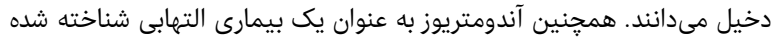

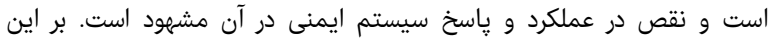

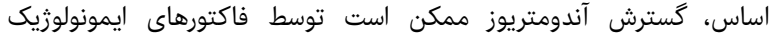

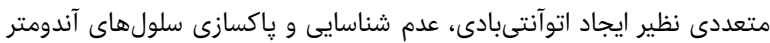

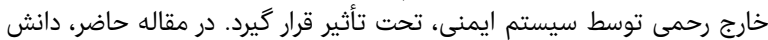

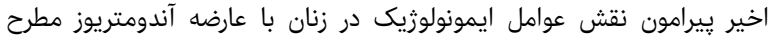

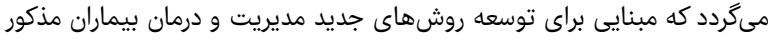

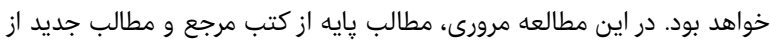
يايكاه اطلاعاتى Science Direct،Pubmed و و و

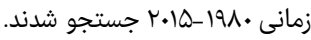

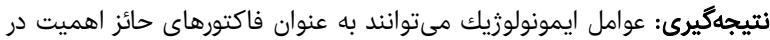

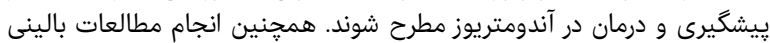

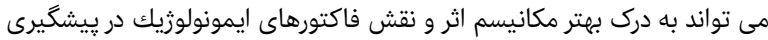
و درمان بيمارى آندومتريوز كمك نمانك ندايد.

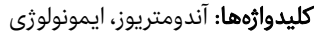

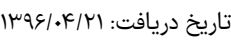

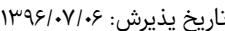

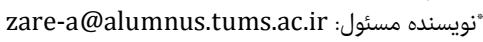

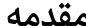

ايجاد بافت آندومتر، طى فرآيند آندومتريوز، اغلب به سبب بيان

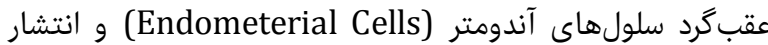

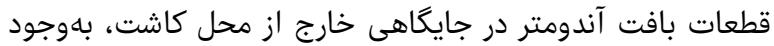

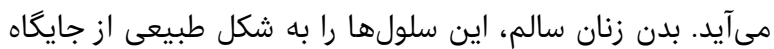

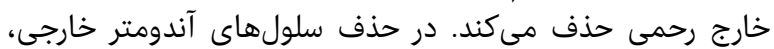

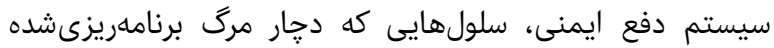

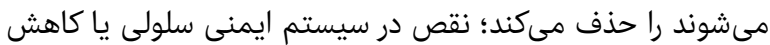

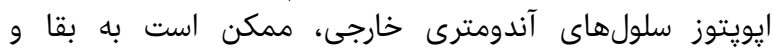

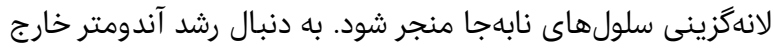

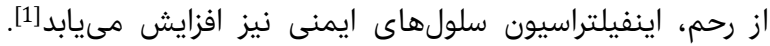

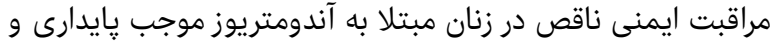

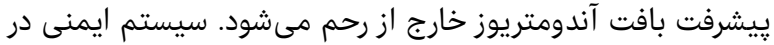

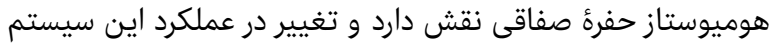

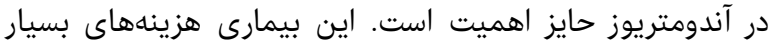

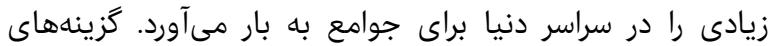

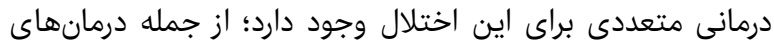

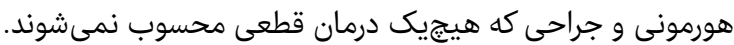

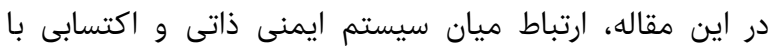

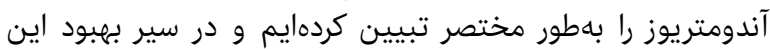




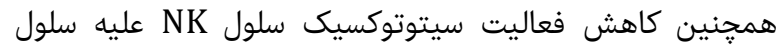

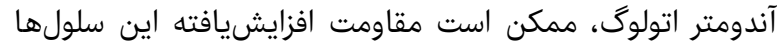

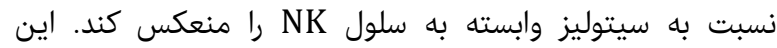

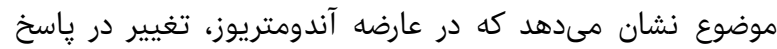

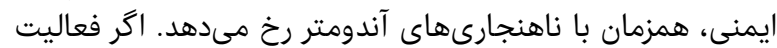

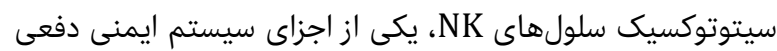

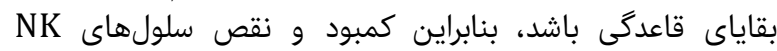

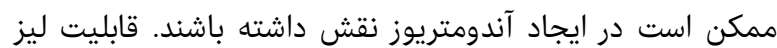

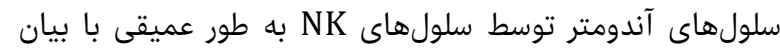

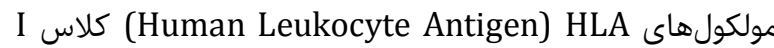
مرتبط است. تعداد مولكولهاى MHC كلاس I I در سلولهاى نابهجا (Ectopic) نسبت به سلولهاى عادى (Eutopic) بيشتر

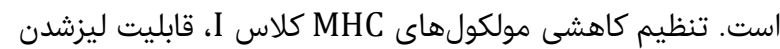

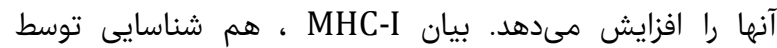
مكانيزم NK، باواسطهى سايتوكاين (بهصورت موضعى، نظير

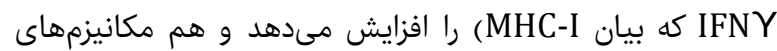

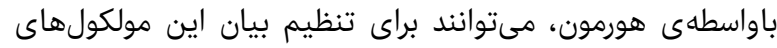
غشايى لازم باشند [6].

سلولهاى NK رحمى، آندومتريوز و نابارورى

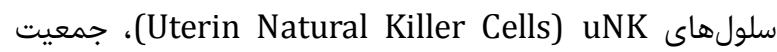
سلولى NK مجزا، در آندومتر رحمى هستند و نقش خاصى بلى براي

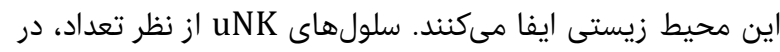

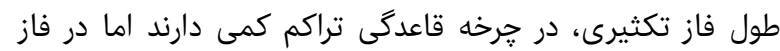

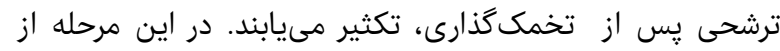

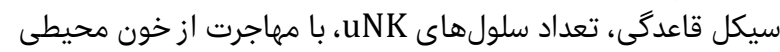

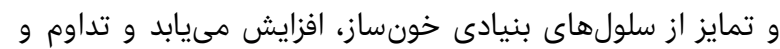

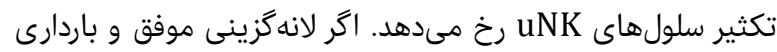

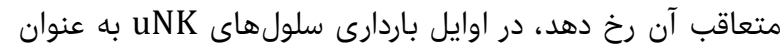

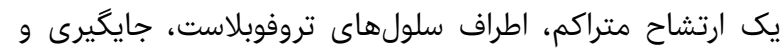

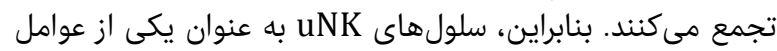

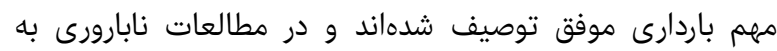

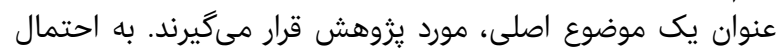

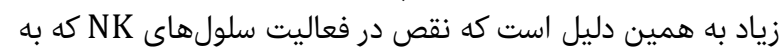

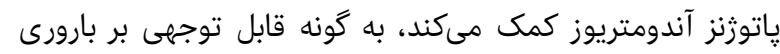

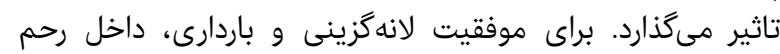

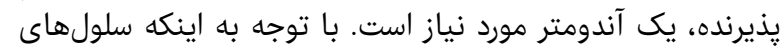

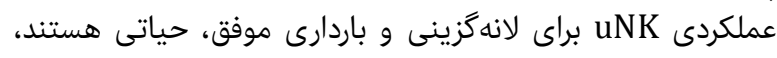

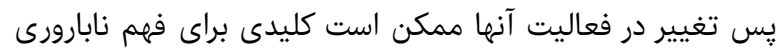
مرتبط با آندومتريوز باشد.

ماستسلها

شواهد، حاكى از وجود التهاب آلرزيك، در عارضه آندومتريوز است.

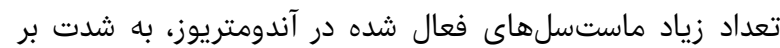

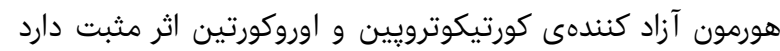

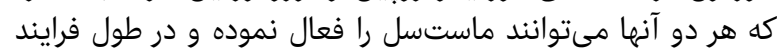

آندومتريوز به شكل فيبروز و التهاب دخالت مغالت كنند [12].

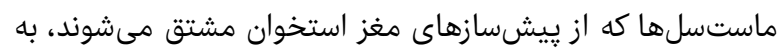

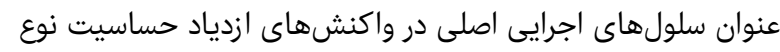

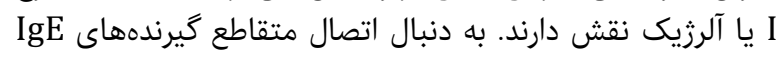

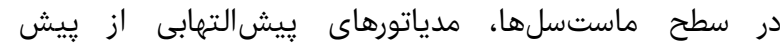

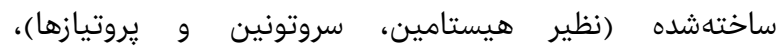
متابوليتهاى اسيداراشيدونيك (لكوترين C4، PGD-2 و PAF) و و
ضايعات آندومتريوتيك و برخى مواد شيميايى، مىتوانند

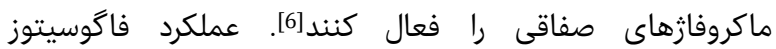

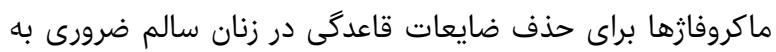

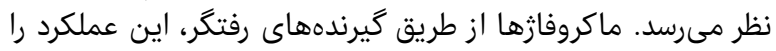

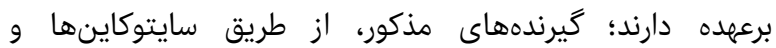

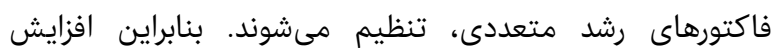

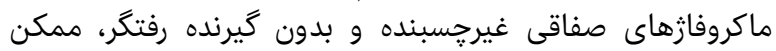

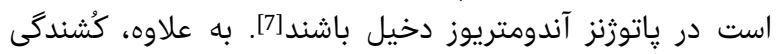

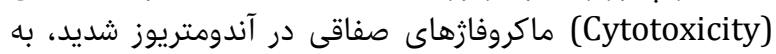

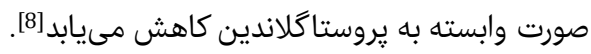
نوتروفيلها نوتروفيلها به عنوان اولين سلول حاضر در التهاب، طول عمر

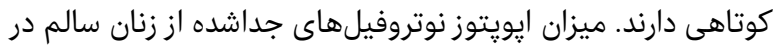

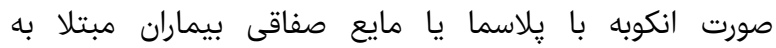
آندومتريوز، كاهش مىيابد [9].

سلولهاى دندريتيك سلولهاى دندريتيك (Dendritic Cells) نوعى از سلولهاى

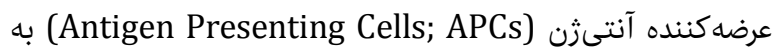

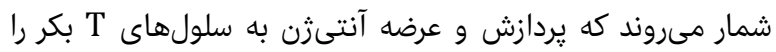

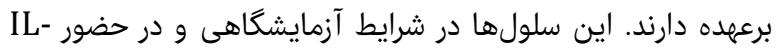
4/GM-CSF

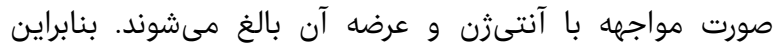

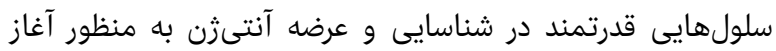

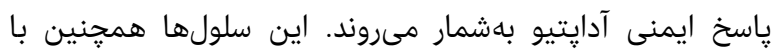

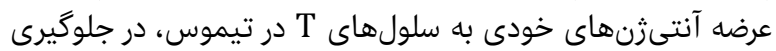

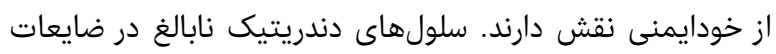

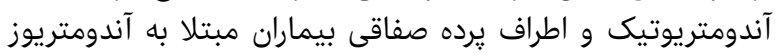

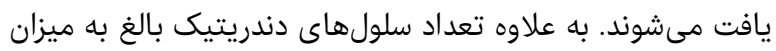

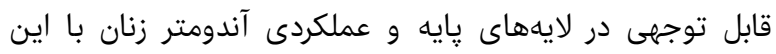
عارضه كاهش مىيابند [10].

سلولهاى كشنده طبيعى (NK)

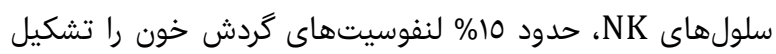

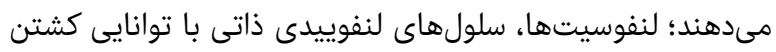

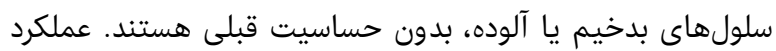

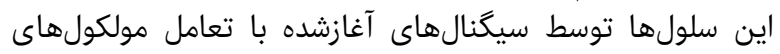

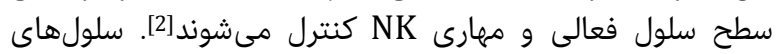

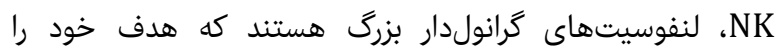

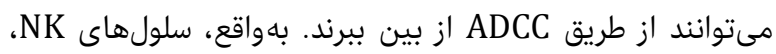

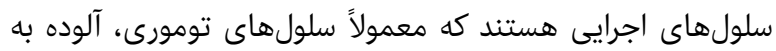

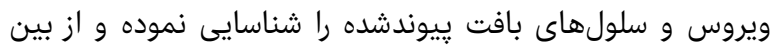

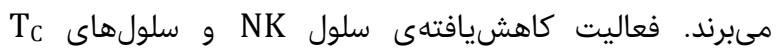

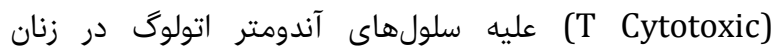
آندومتريوز شناسايىشده است كه با مرحله بيماريه آندارئ مرتبط است.

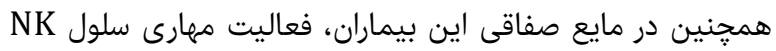

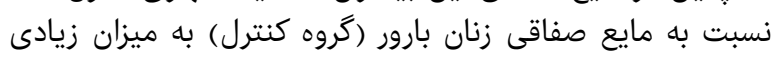

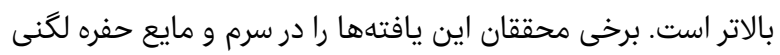

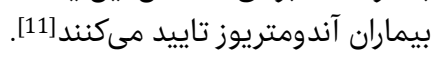

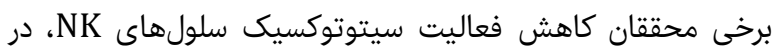

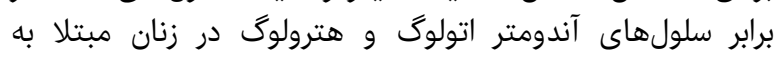

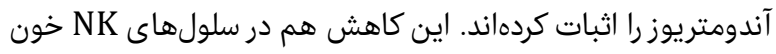
محيطى و هم سلولهاى NK صفاقى مشاهده شده است آن. 


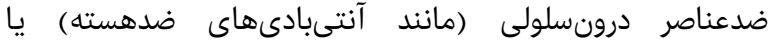

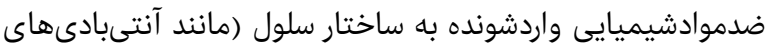

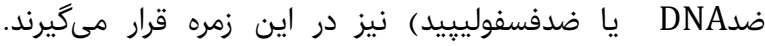

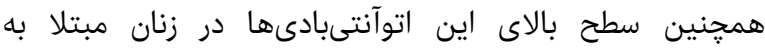

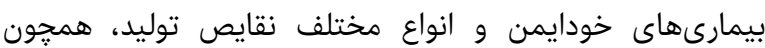

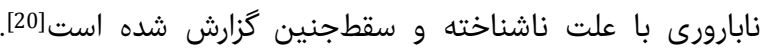

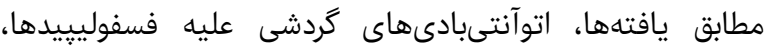

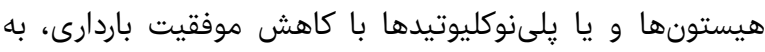

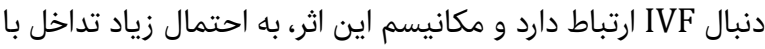

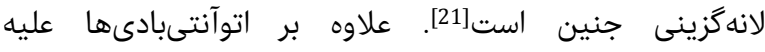

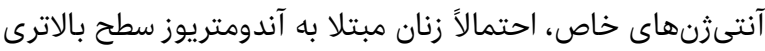

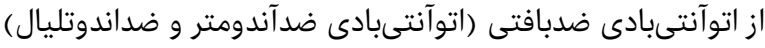

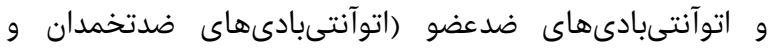

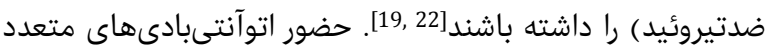

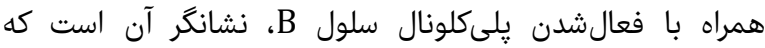

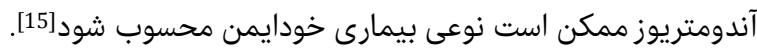

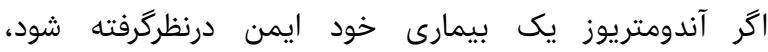

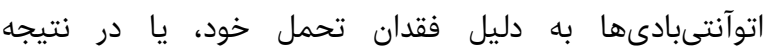

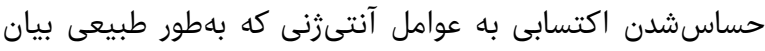

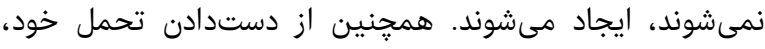

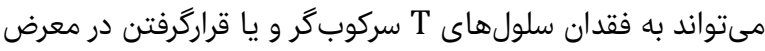
فعال كنندهاى بسيار قوى سلول B منجر شود [1]. ايمنى باواسطه سلول

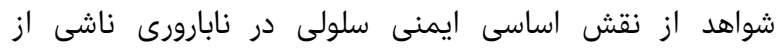

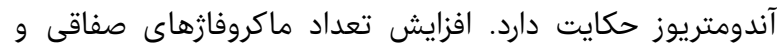

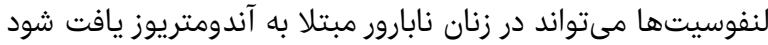

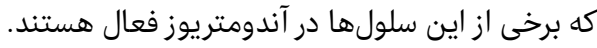

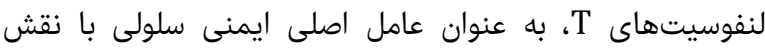

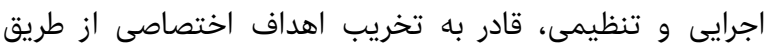

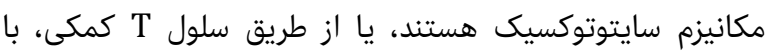

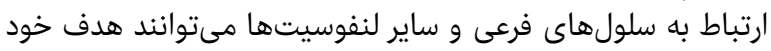

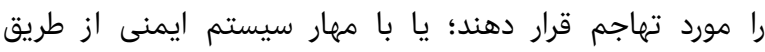

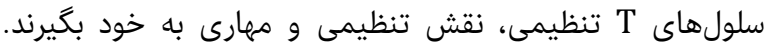

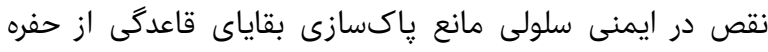

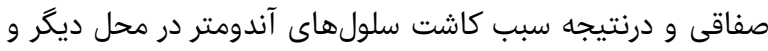

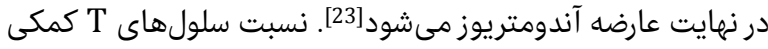

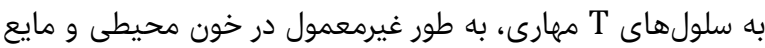

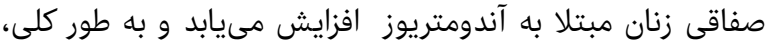

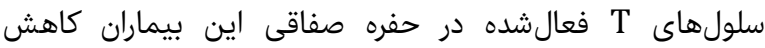

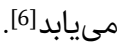

برهم كنش، بين سلولهاي T T و ماتريكس خارج سلولى در زنان

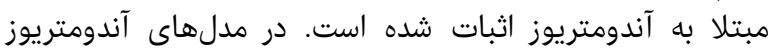

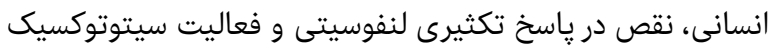

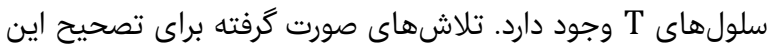

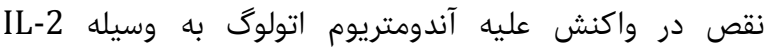
اميدبخش بوده است] [24].

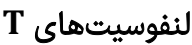

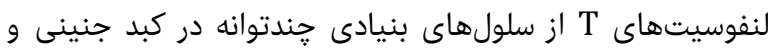

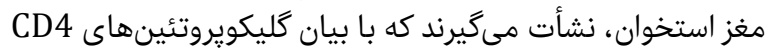

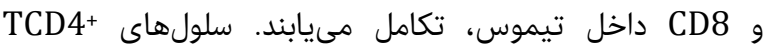

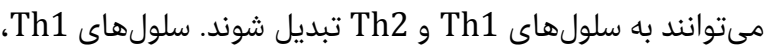

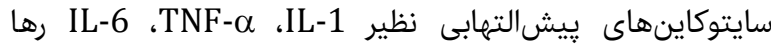

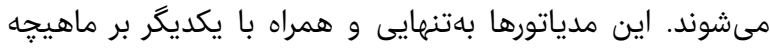

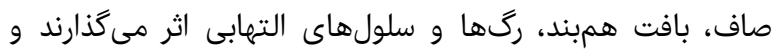

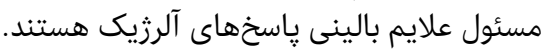

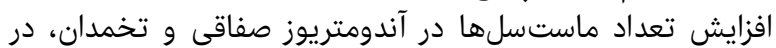

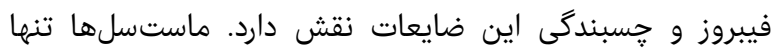
سلولهايى هستند كه TNF-

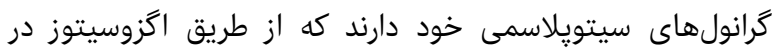

ضايعات آندومتريوتيك رها مى شوند [12].

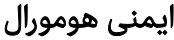

آننى بادى ها يا ايمونوكلبولينها كه محصول اصلى ايمنى هومورال

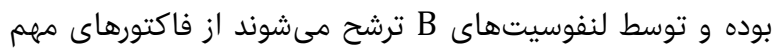

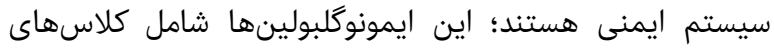
IgD ، و و IgA ،IgG ،IgM آندومتريوز مورد مطالعه قرار گرفته است.

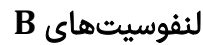

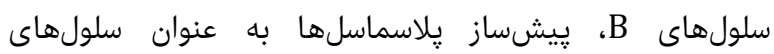

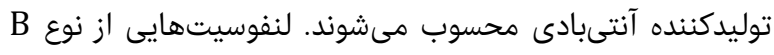

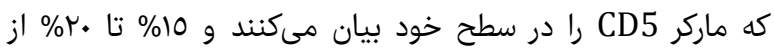

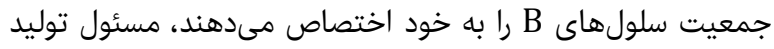

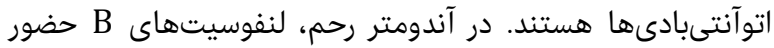
كستردهاى دارند [1]. به دنبال عارضه آندومتريوز، رسوب موضعى ايمونوكلبولينهاى

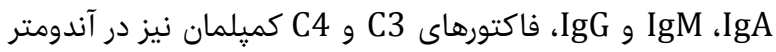

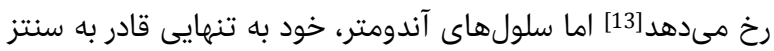

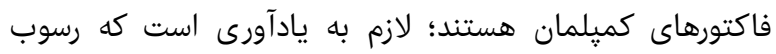

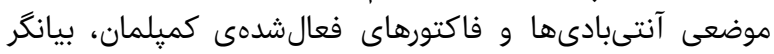

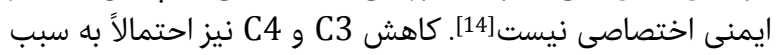

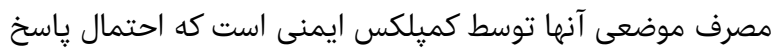

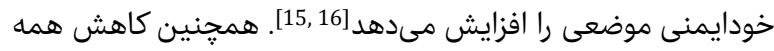

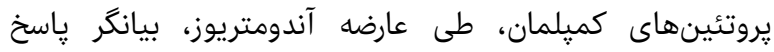

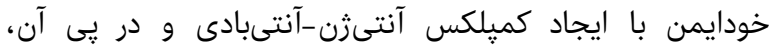

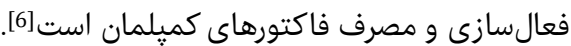

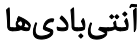

آنتىبادىهاى ضدآندومتر در داخل سرم، مايع صفاقى و كاشتهاى آنساى

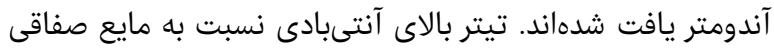

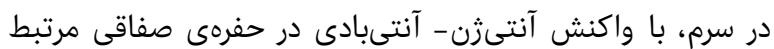

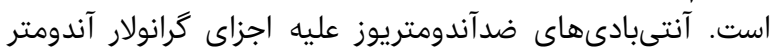

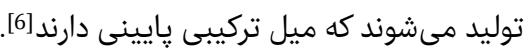

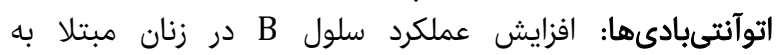

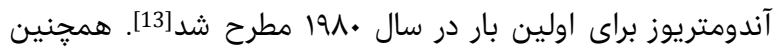

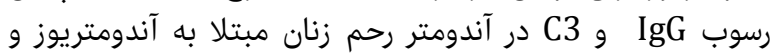

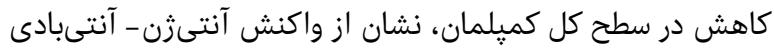

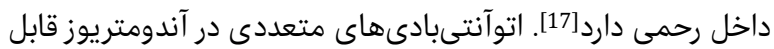

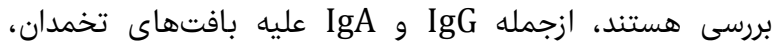

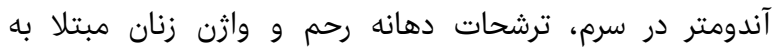

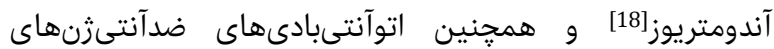

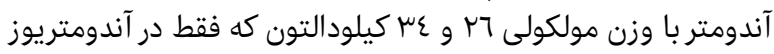

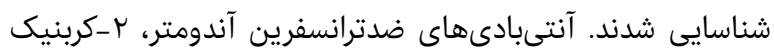
انهيدراز و كليكويروتئين (Alpha 2 Heremans Schmidt) نيز در اين بيماران يافت شده است[19]. اتوآنتىبادىهاى گردشى، 


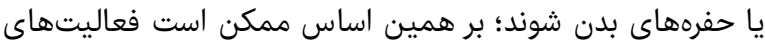
اندوكرينى داشته باشند [11].

سايتوكاينها در سيستم ايمنى، مدياتورهاى كليدى ارتينى ارتباط بين

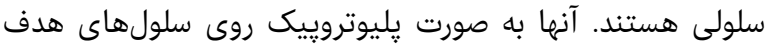

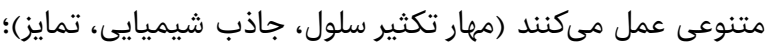

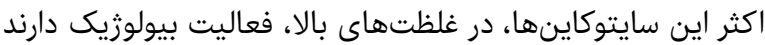

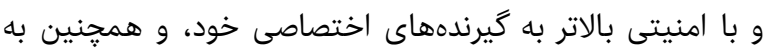

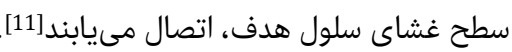

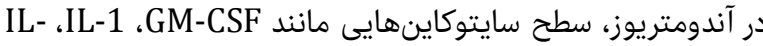

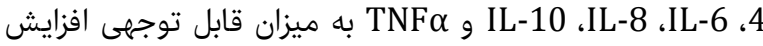
مىيابد. علاوه بر سايتوكاينها، عوامل رشد متعددى مانند

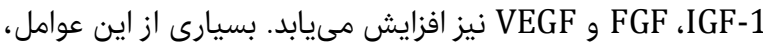

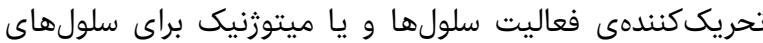
آندومتر هستند [24]. آندومتر طبيعى عوامل مختلف موثر بر سيستم ايمنى بدن (مانند

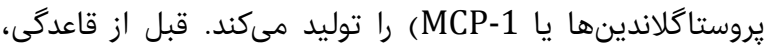

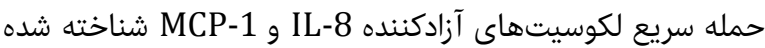

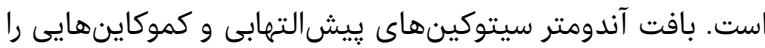

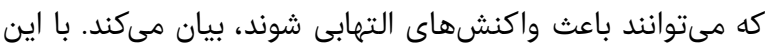

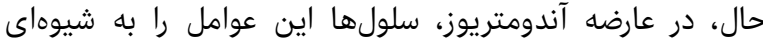

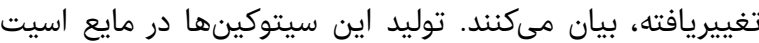

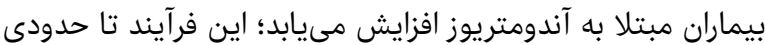

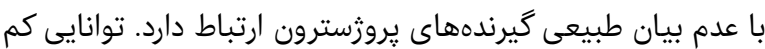

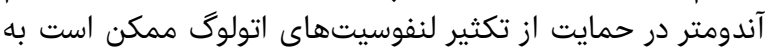

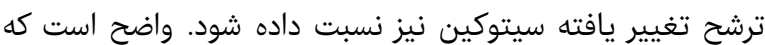

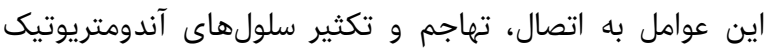

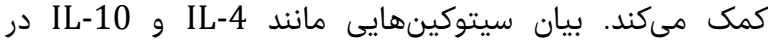

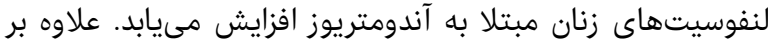

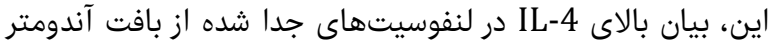

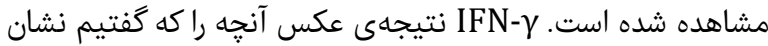

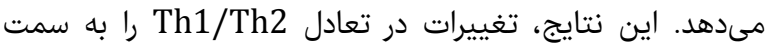

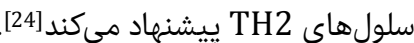

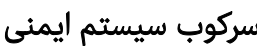

به نظر مىرسد در محافظت افئمي افراد مبتلا به آندومتريوز در مقابل

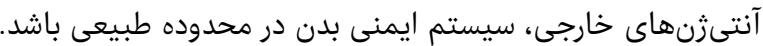

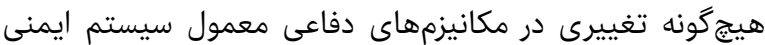

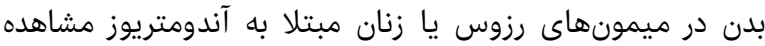

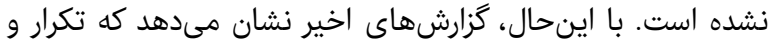

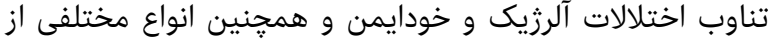

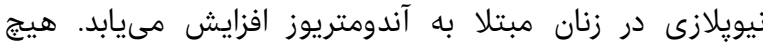

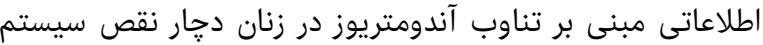

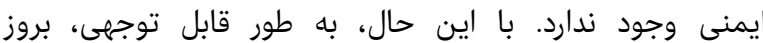

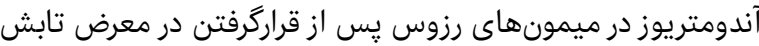

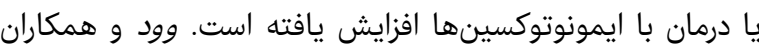

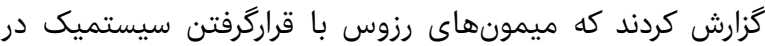

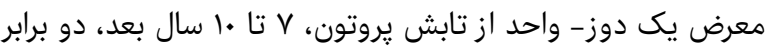

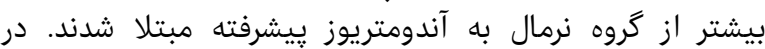

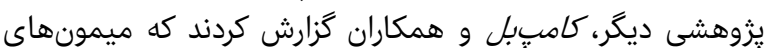

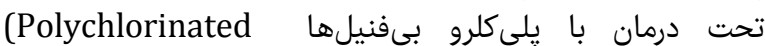

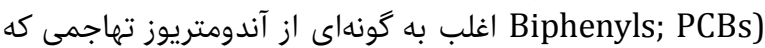

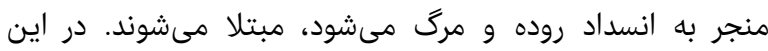

نسبت سلولهاى +CD8 را به سلولهاى كشنده افزايش مىدهند و

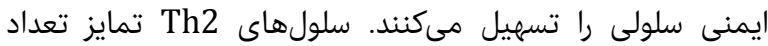
سلولهاى B را به سلولهاى ترشحكنينده آنتىبادى تقويت مئىكنيند.

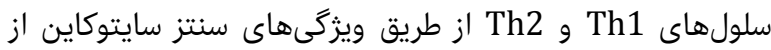
يكديكر تفكيك مى شوند. سلولهاى

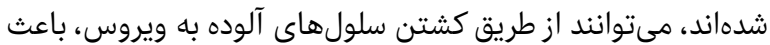

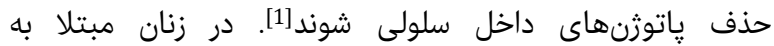

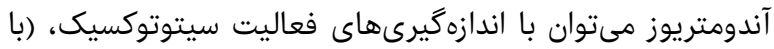

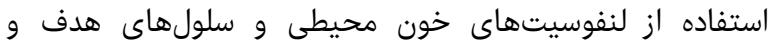

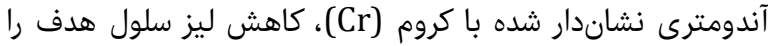

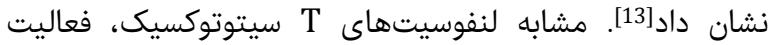
سلولهاى Th در مايع صفاقى نيز كاهش مى مابه لنفابد كه اين مساله

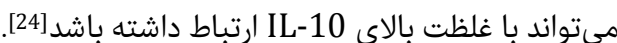

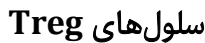
اين سلولها به عنوان زيرگروهى از سلولهاى 'CD4 خون النون محيطى،

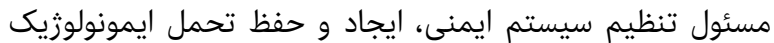
هستند كه با توليد سايتوكاينهاى مهارى

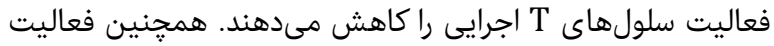

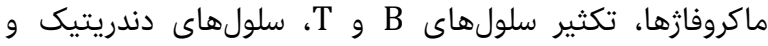

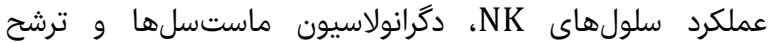

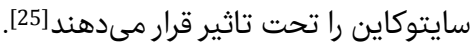

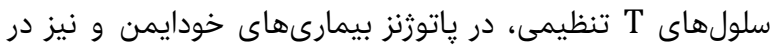

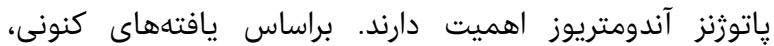

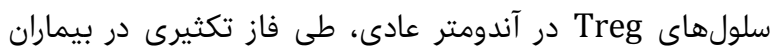

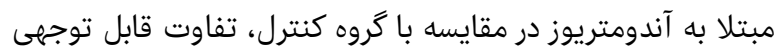

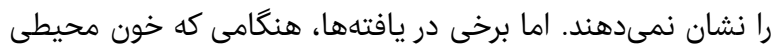

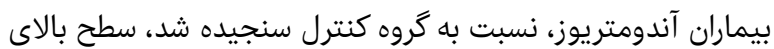

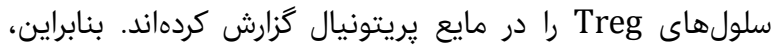

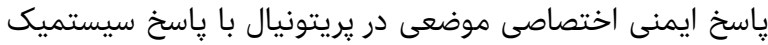

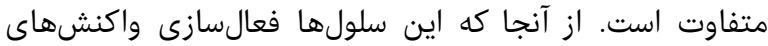

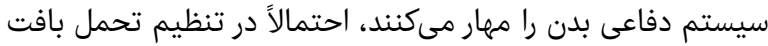

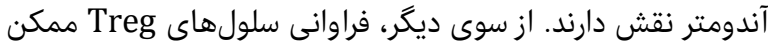

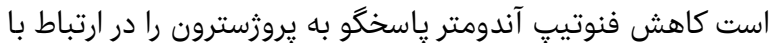

آندومتريوز منعكس كند [24].

سلولهاى Th17 سلولهاىTh17 زيركروه جديدى از لنفوسسيتهاى Th17 محسوب

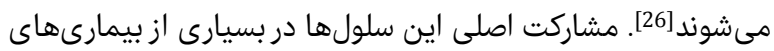

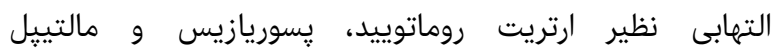
اسكلروزيس اثبات شده است. سلولهاى Th17 با توليد و ترشح

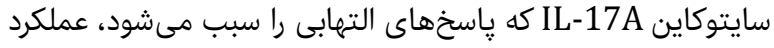

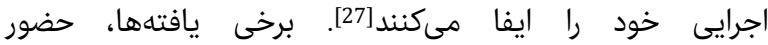

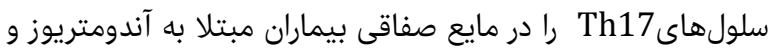

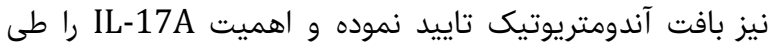
آندومتريوز نشان مىدهند [28]

سايتوكاينها و فاكتورهاى رشد ماند مرتبط با آندومتريوز

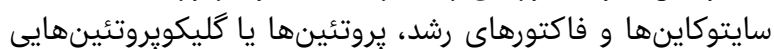

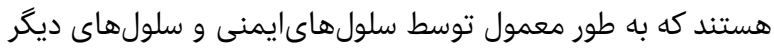

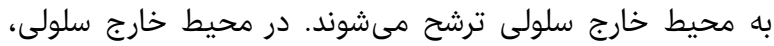

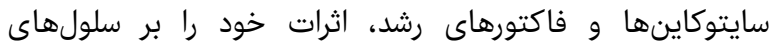

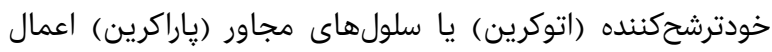

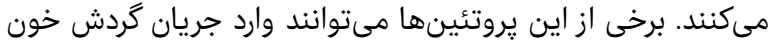


التهابى در محل كاشت خارج رحم است، مىتوان نتيجه گرقفت كه

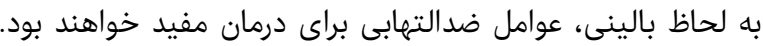

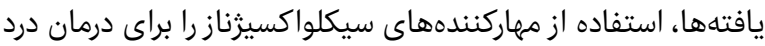

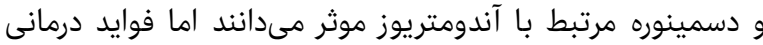

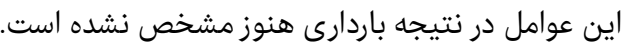
اندروزن به طور گسترده در درمان آندومتريوز استفاده إنداه

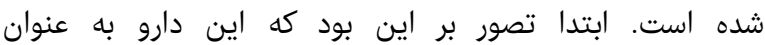

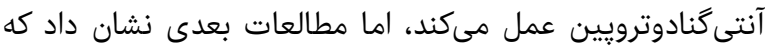

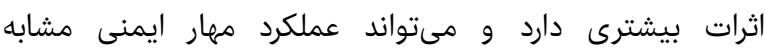

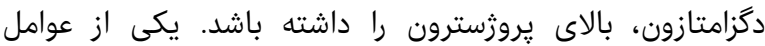

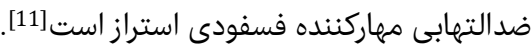

بحث اينكه به جه دليل برخى از خانمها به آندومتريوز مبتلا مى شوند،

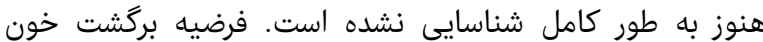

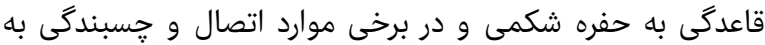

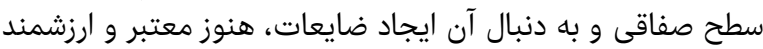

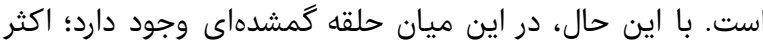

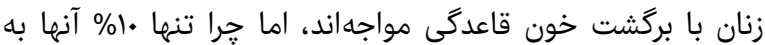

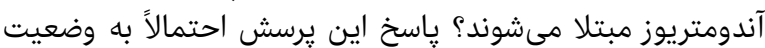

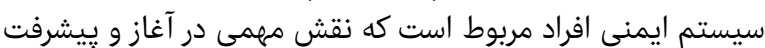

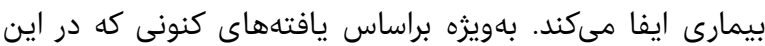

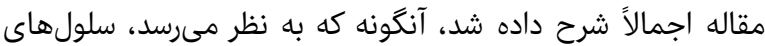

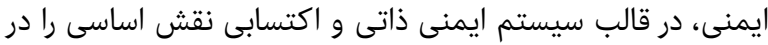

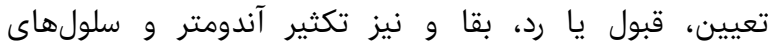

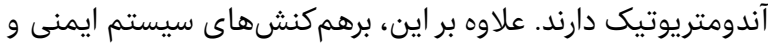

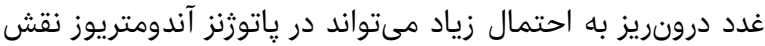

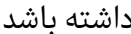

\section{نتيجه}

در حال حاضر، آندومتريوز به عنوان يك بيمارى با نقص دري سيستم

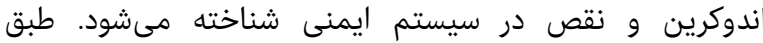

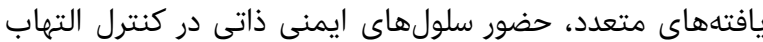

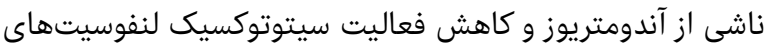

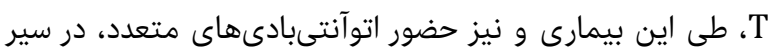

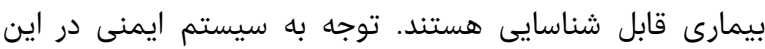

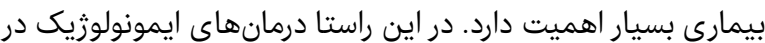

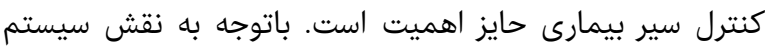

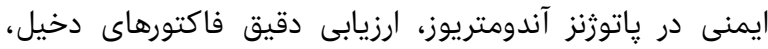

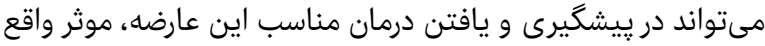
شود.

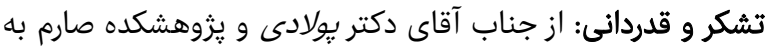

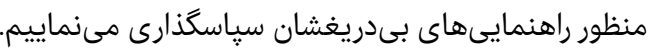

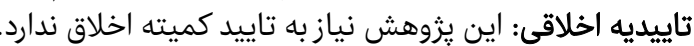

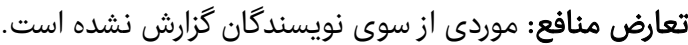

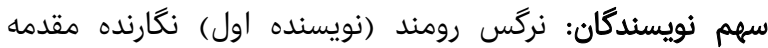

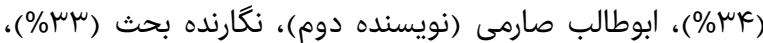

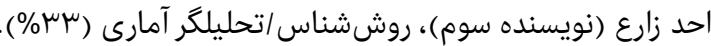

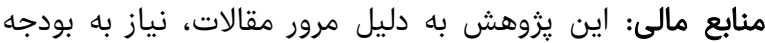

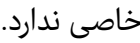

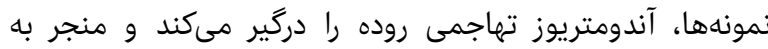

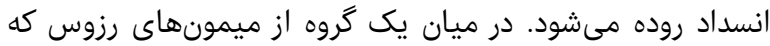

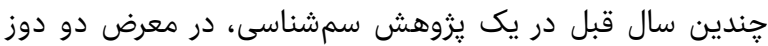

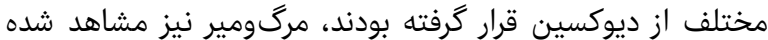

كزينههاى درمانى متعددى براى اين اختلال وجود دارد كه از جمله

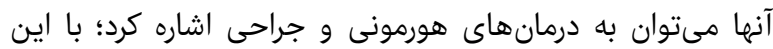

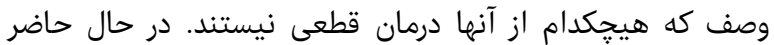

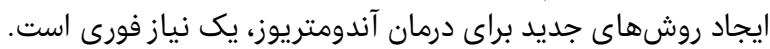

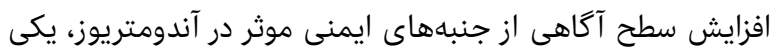

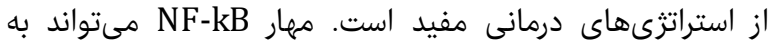

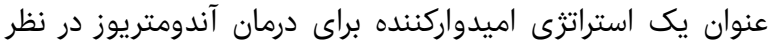

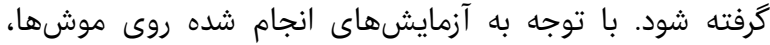

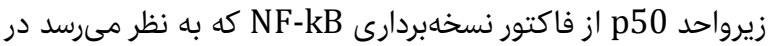

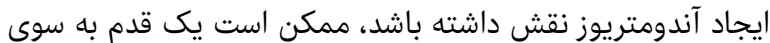

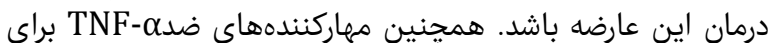

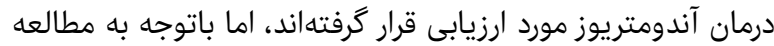

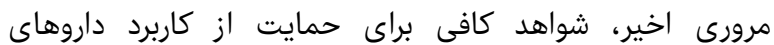

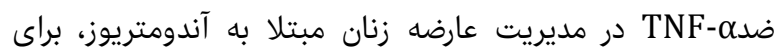
تسكين درد لكن وجود ندارد. روشهارى درمانه درانى ديكر هنوز در مرحله

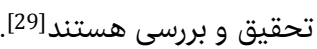
با توجه به مقاومت ذاتى سلولهاى آندائ آندومترى نسبت به إيويتوز،

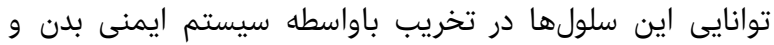

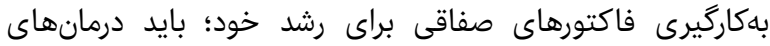

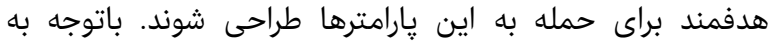

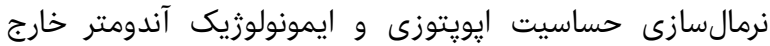

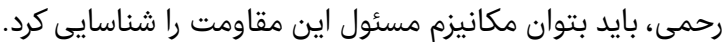

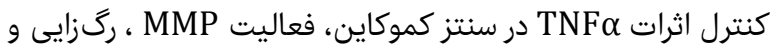

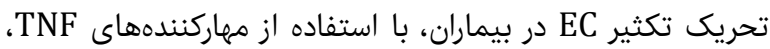

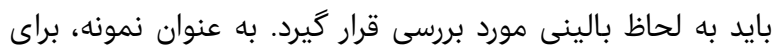

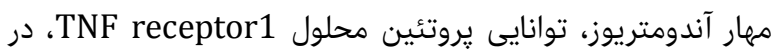

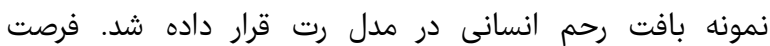

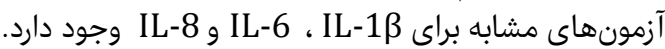

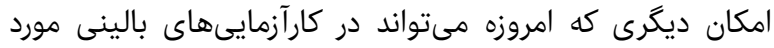

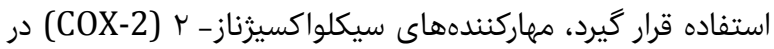

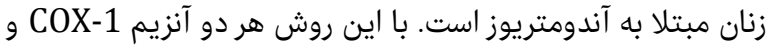

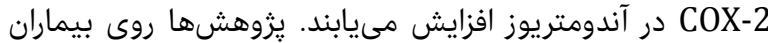

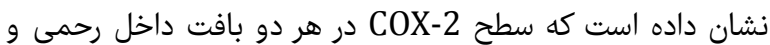

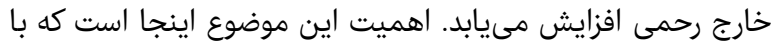

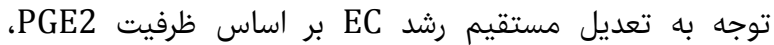

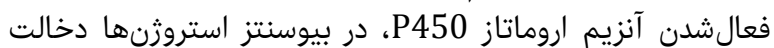

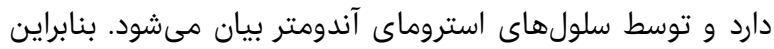

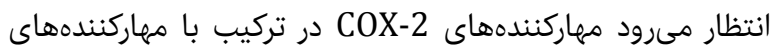

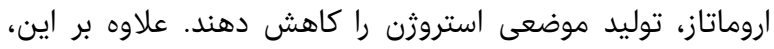

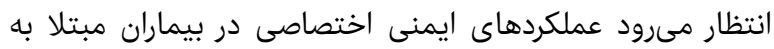

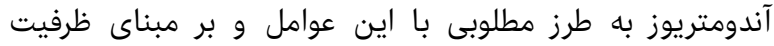

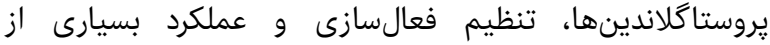

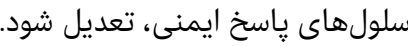

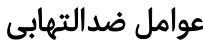
اگر علايم و نشانكان آندومتريوز، منعكسكننده واكنشهاى 
ايمونولوزى اندومتريوز؛ مطالعه مرورى سيستماتيك اس

endometriotic tissue. Fertil Steril. 1991;55(2):395-402.

15- Gleicher N, el-Roeiy A, Confino E, Friberg J. Is endometriosis an autoimmune disease?. Obstet Gynecol. 1987;70(1):115-22.

16- Meek SC, Hodge DD, Musich JR. Autoimmunity in infertile patients with endometriosis. Am J Obstet Gynecol. 1988;158(6 Pt 1):1365-73.

17- Weed JC, Arquembourg PC. Endometriosis: can it produce an autoimmune response resulting in infertility?. Clin Obstet Gynecol. 1980;23(3):885-93.

18- Mathur S, Peress MR, Williamson HO, Youmans CD, Maney SA, Garvin AJ, et al. Autoimmunity to endometrium and ovary in endometriosis. Clin Exp Immunol. 1982;50(2):259-66.

19- Mathur SP. Autoimmunity in endometriosis: Relevance to infertility. Am J Reprod Immunol. 2000;44(2):89-95.

20- Ota H, Igarashi S, Hatazawa J, Tanaka T. Is adenomyosis an immune disease?. Hum Reprod Update. 1998;4(4):360-7.

21- Dmowski WP, Rana N, Michalowska J, Friberg J, Papierniak C, el-Roeiy A. The effect of endometriosis, its stage and activity, and of autoantibodies on in vitro fertilization and embryo transfer success rates. Fertil Steril. 1995;63(3):555-62.

22- Nothnick WB. Treating endometriosis as an autoimmune disease. Fertil Steril. 2001;76(2):223-31.

23- Dmowski WP, Steele RW, Baker GF. Deficient cellular immunity in endometriosis. Am J Obstet Gynecol. 1981;141(4):377-83.

24- Kralickova M, Vetvicka V. Immunological aspects of endometriosis: A review. Ann Transl Med. 2015;3(11):153.

25- Gogacz M, Winkler I, Bojarska-Junak A, Tabarkiewicz J, Semczuk A, Rechberger $T$, et al. $T$ regulatory lymphocytes in patients with endometriosis. Mol Med Rep. 2014;10(2):1072-6.

26- Miossec P, Korn T, Kuchroo VK. Interleukin-17 and type 17 helper T cells. N Engl J Med. 2009;361(9):88898.

27- Tesmer LA, Lundy SK, Sarkar S, Fox DA. Th17 cells in human disease. Immunol Rev. 2008;223:87-113.

28- Hirata T, Osuga Y, Takamura M, Kodama A, Hirota Y, Koga K, et al. Recruitment of CCR6-expressing Th17 cells by CCL 20 secreted from IL-1 beta-, TNF-alpha-, and IL17A-stimulated endometriotic stromal cells. Endocrinology. 2010;151(11):5468-76.

29- Olovsson M. Immunological aspects of endometriosis: An update. Am J Reprod Immunol. 2011;66(Suppl 1):101-4.

1- Dmowski WP, Braun DP. Immunology of endometriosis. Best Pract Res Clin Obstet Gynaecol. 2004;18(2):245-63.

2- Thiruchelvam U, Wingfield M, O'Farrelly C. Natural killer cells: Key players in endometriosis. Am J Reprod Immunol. 2015;74(4):291-301.

3- Zeller JM, Henig I, Radwanska E, Dmowski WP. Enhancement of human monocyte and peritoneal macrophage chemiluminescence activities in women with endometriosis. Am J Reprod Immunol. 1987;13(3):78-82.

4- Braun DP, Gebel H, House R, Rana N, Dmowski NP. Spontaneous and induced synthesis of cytokines by peripheral blood monocytes in patients with endometriosis. Fertil Steril. 1996;65(6):1125-9.

5- Braun DP, Ding J, Dmowski WP. Peritoneal fluidmediated enhancement of eutopic and ectopic endometrial cell proliferation is dependent on tumor necrosis factor-alpha in women with endometriosis. Fertil Steril. 2002;78(4):727-32.

6- Vinatier D, Dufour P, Oosterlynck D. Immunological aspects of endometriosis. Hum Reprod Update. 1996;2(5):371-84.

7- Santanam N, Song M, Rong R, Murphy AA, Parthasarathy S. Atherosclerosis, oxidation and endometriosis. Free Radic Res. 2002;36(12):1315-21.

8- Braun DP, Gebel H, Rotman C, Rana N, Dmowski WP. The development of cytotoxicity in peritoneal macrophages from women with endometriosis. Fertil Steril. 1992;57(6):1203-10.

9- Kwak JY, Park SW, Kim KH, Na YJ, Lee KS. Modulation of neutrophil apoptosis by plasma and peritoneal fluid from patients with advanced endometriosis. Hum Reprod. 2002;17(3):595-600.

10- Schulke L, Berbic M, Manconi F, Tokushige N, Markham R, Fraser IS. Dendritic cell populations in the eutopic and ectopic endometrium of women with endometriosis. Hum Reprod. 2009;24(7):1695-703.

11- Lebovic DI, Mueller MD, Taylor RN. Immunobiology of endometriosis. Fertil Steril. 2001;75(1):1-10.

12- D'Cruz OJ, Uckun FM. Targeting mast cells in endometriosis with janus kinase 3 inhibitor, JANEX-1 Am J Reprod Immunol. 2007;58(2):75-97.

13- Startseva NV. Clinical immunological aspects of genital endometriosis. Akush Ginekol (Mosk). 1980;(3):23-6. [Russian]

14- Isaacson $\mathrm{KB}, \mathrm{Xu} \mathrm{Q}$, Lyttle CR. The effect of estradiol on the production and secretion of complement component 3 by the rat uterus and surgically induced 